\title{
KRITIK TERHADAP KONSEP TANZIL NASR HAMID ABU ZAYD DAN IMPLIKASINYA TERHADAP STATUS AL- QUR'AN
}

\author{
Muzayyin
}

IAINU Kebumen

Email: muzayyinbdws@gmail.com

\begin{abstract}
This paper intends to present Tanzil Nasr Hamid Abu Zayd's ideas or concepts and their implications for the status of the Qur'an, to then provide adequate criticism of it. In the first section, the concept of Tanzil, according to Nasr Hamid, which was later imitated by several Indonesian thinkers, will then seek relevance to the ideas put forward by Orentalis. The second part, the implication of the concept of Tanzil Nasr Hamid on the status of the Qur'an, which in it breaks down the new terms of the Qur'an are cultural products (muntaj thasaqafi), Producers of Culture (muntij thasaqafi) and language texts (lashawi nash) the third part is followed by a critical analysis of the concept of Tanzil Nasr Hamid and the implications of Nasr Hamid's tanzil concept on the status of the Qur'an.

Tulisan ini bermaksud untuk memaparkan gagasan atau konsep Tanzil Nasr Hamid Abu Zayd dan Implikasinya terhadap status Al-Qur'an, untuk kemudian memberikan kritik yang memadai terhadapnya. Pada bagian pertama, akan dipaparkan tentang konsep Tanzil menurut Nasr Hamid yang kemudian ditiru oleh beberapa pemikir Indonesia, baru kemudian mencari relevansinya dengan gagasan yang dikemukakan oleh Orentalis. Bagian kedua, Implikasi konsep Tanzil Nasr Hamid terhadap status Al-Qur'an, yang didalamnya mengurai terma-terma baru tentang al-Qur'an adalah produk budaya (muntaj thasaqafi), Produsen Budaya (muntij thasaqafi) dan teks bahasa (nash lughawi).bagian ketiga ialah dilanjutkan dengan analisis kritis terhadap konsep Tanzil Nasr Hamid dan Implikasi konsep tanzil Nasr Hamid terhadap status al-Qur'an.
\end{abstract}

Keywords: Tanzil, Al-Qur'an, Hermeneutika Liberal, Rasionalisme, lawh mabfuz. 


\section{Pendahuluan}

Salah satu isu kontroversial yang hingga saat ini seringkali dipertentangkan oleh para pemikir liberal ${ }^{1}$ ialah konsep tanzil. Pemahaman bahwa al-Qur'an adalah kalam Allah yang ditanzilkan kepada Nabi Muhammad saw melalui malaikat Jibril, baik lafazh maupun maknanya, ${ }^{2}$ didekonstruksi oleh pemikir liberal dengan berusaha mengajukan konsep barunya. ialah Nasr Hamid Abu Zayd (1943-2010) seorang pemikir muslim asal Mesir, menyatakan dengan tegas bahwa teks al-Qur'an ketika di-tan₹il-kan kepada Nabi Muhammad berupa makna saja karena problem bahasa. Oleh karena itu, agar bagaimana bahasa Tuhan dipahami oleh ummat Islam maka Muhammad harus membahasakan dengan bahasa Arabnya. ${ }^{3}$ Sehingga menurutnya jika Tuhan berbicara dengan bahasa Tuhan, manusia (Nabi) tidak akan mengerti. Suatu pemahaman yang mirip dengan konsep hermes, tokoh dalam mitodelogi Yunani yang bertugas menyampaikan pesan dewa Zeus kepada manusia, menjelaskan bahasanya yang awalnya menggunakan bahasa langit menjadi bahasa bumi agar bisa dimengerti oleh manusia. ${ }^{4}$ Oleh karena itu, dalam pandangan Nasr

${ }^{1}$ Kata-kata liberal diambil dari bahasa latin liber artinya bebas dan bukan budak atau suatu keadaan dimana seseorang itu bebas dari kepemilikan orang lain. Makna bebas kemudian menjadi sebuah sikap kelas masyarakat terpelajar di Barat yang membuka pintu kebebasan berfikir (The Old Liberalism). Lihat: Hamid Fahmy Zarkasyi , Liberalisasi Pemikiran Islam, (CIOS-ISID-Gontor, 2009), 25; Penisbatan liberal kepada Islamolog kontemporer seperti; Nasr Hamid Abu Zayd, dan cendekiawan muslim Indonesia lainnya, yang didasarkan atas gagasan berfikirnya yang lebih menekankan superioritas akal daripada wahyu.

2 Jalaluddin As-Suyuti as- Syafi'i, Al-Itqan Fi Ulum al-Qur'an, (Beirut: Darul fikr, 2005),Juz 1. 63.

${ }^{3}$ Hal ini seperti yang diungkapkannya dalam bukunya "Voice of an Exile, The "The word of Mubammad reporting what he asserts is the Word of God. This is the Qur'an". Dia juga menyatakan " The word of God needed to adapt itself become human, because God wanted to communicate to human beings. If God spoke God-language, buman beings would understand nothing.Lihat: Nasr Hamid Abu Zayd dan Ester R. Nelson, Voice of an Exile: Reflection on Islam, (London: Westport, Connecticut, 2004), 57.

${ }^{4}$ Lihat: Warner G. Jeanrond, The theological Hermeneutcs: Development and Significance, (New York: Crossroad, 1991), 1.

154 | TAJDID Vol. 17, No. 2, Juli - Desember 2018 
Hamid al-Qur'an adalah merupakan spirit wahyu yang disaring melalui Muhammad sekaligus diekspresikan dalam batas kemampuan linguistiknya yang dipengaruhi oleh kondisi kejiwaan, social, dan budaya setempat. Dengan asumsi tersebut, Nasr Hamid menilai Nabi Muhammad sebagai seorang yang ummy, bukanlah penerima pasif wahyu, tetapi juga mengolah redaksi al-Qur'an sesuai dengan kondisinya sebagai manusia biasa. ${ }^{5}$

Sebagai konsekuensi logis, Aksioma semacam itu berimplikasi terhadap kedudukan atau sakralitas al-Qur'an, yang awalnya bersifat transenden berubah menjadi teks yang bersifat profan. Hal itu bukan tidak mungkin terjadi sebab seperti asumsi yang dibangun oleh Nasr Hamid teks sejak awal diturunkan ketika teks diwahyukan dan dibaca oleh Nabi, ia berubah dari teks ilahi (nas ilahi) menjadi sebuah konsep atau teks manusiawi (nas insani), karena ia berubah dari tanzil menjadi takwil. Pemahaman Muhammad atas teks merepresentasikan tahap paling awal dalam interaksi teks dengan akal manusia. ${ }^{6}$ Karena teks al-Qur'an telah menjadi teks manusiawi yang terbentuk dalam realitas dan budaya, maka Nasr Hamid berkesimpulan al-Qur'an adalah produk budaya (muntaj thaqafi), selain itu ia juga menjadi produsen budaya (muntij thaqafi) karena menjadi teks yang hegemonik dan menjadi rujukan bagi teks-teks lain. ${ }^{7}$ disebabkan realitas dan budaya tidak bisa dipisahkan dari bahasa manusia, maka Nasr Hamid juga menganggap al-Qur'an sebagai teks bahasa (nas lughawi). ${ }^{8}$ Dengan berpendapat seperti itu, Nasr Hamid juga menegaskan bahwa teks-

${ }^{5}$ Konsep yang menyatakan bahwa teks al-Qur'an sebagai spirit wahyu dari Tuhan identik dengan konsep teks Bibel, bahwa "The whole Bible is given by inspiration of God." Lihat: Adian Husaini dan Hendri Salahuddin, Studi Komparatif: Konsep al-Qur'an Nashr Hamid dan Mu'tazilah, Majalah Islamia, Thn 1 No. 2/Junigustus 2004, 34.

${ }^{6}$ Lihat: Nasr Hamid Abu Zayd, Kritik Wacana Agama, Terj. Khoiron Nahdiyyin. (Yogyakarta: LKiS 2003), 98.

7 Nasr Hamid Abu Zayd, Mafhum al-Nas: Dirasah fi' Ulum Al-Qur'an (Beirut: al-Markaz al-Thaqafi al-Arabi, edisi II, 1994), 97.

8 Nasr Hamid Abu Zayd, Mafbum al-Nas, 10;18

TAJDID vol. 17, No. 2, Juli - Desember 2018 | 155 
teks keagamaan sama bentuknya dengan teks-teks lain dalam budaya. $^{9}$

Maka dari itu, Nasr Hamid Abu Zayd berpendapat bahwa keabsolutan al-Qur'an yang sakral sebatas dalam bentuknya yang metafisis atau saat berada di lawh mahfuz yang tidak diketahui hakekatnya dan tidak dapat dibuktikan melainkan hanya sekedar cerita dari al-Qur'an saja. Faktanya pandangan Nasr Hamid yaitu tentang konsep tanzil dan tekstualitas al-Qur'an ini ditiru oleh beberapa pemikir Indonesia sebagaimana yang akan dibahas dalam makalah singkat ini. atas dasar itulah, tulisan ini bermaksud untuk memaparkan gagasan atau konsep Tanzil Nasr Hamid Abu Zayd dan Implikasinya terhadap status Al-Qur'an, untuk kemudian memberikan kritik yang memadai terhadapnya. Pada bagian pertama, akan dipaparkan tentang konsep Tanzil menurut Nasr Hamid yang kemudian ditiru oleh beberapa pemikir Indonesia, baru kemudian mencari relevansinya dengan gagasan yang dikemukakan oleh Orentalis. Bagian kedua, Implikasi konsep Tanzil Nasr Hamid terhadap status Al-Qur'an, yang didalamnya mengurai terma-terma baru tentang al-Qur'an adalah produk budaya (muntaj thasaqafi), Produsen Budaya (muntij thasaqafi) dan teks bahasa (nash lughawi).bagian ketiga ialah dilanjutkan dengan analisis kritis terhadap konsep Tanzil Nasr Hamid dan Implikasi konsep tanzil Nasr Hamid terhadap status al-Qur'an.

\section{Konsep Tanzil Nasr Hamid Abu Zayd}

Abu Zayd memandang proses pewahyuan di dalam sinaran teori model komunikasi Roman Jakobson. Hal ini disebabkan karena wahyu adalah proses penyampaian pesan, sementara perkataan Allah (kalam Allah) adalah pesan (risalah). ${ }^{10}$ "proses pewabyuan tidak lain adalah sebuah tindak komunikasi (act of communication) yang secara natural terdiri dari pembicara, yaitu Allab,

9 Nasr Hamid Abu Zayd, Kritik W acana Agama, 215.

${ }^{10}$ Moch Nur Ichwan, Meretas Keserjanaan Kritis Al-Qur'an Teori Hermenentika Nasr Hamid Abu Zayd, (Jakarta: TERAJU, 2003), 69-70

156 | TAJDID vol. 17, No. 2, Juli - Desember 2018 
seorang penerima, yakni Nabi Mubammad, sebuah kode komunikasi, yakni bahasa Arab, dan sebuah canel, yakni Rub Suci (Jibril).” Abu Zayd menolak untuk mendiskusikan factor pembicara (Allah), bukan karena dia menolak keberadaan Allah atau menolak sumber ilahiah Al-Qur'an, tetapi karena pembicara, dalam konteks ini Allah, berada di luar investigasi ilmiah. Di sini, secara implisit dia memproklamirkan "kematian (Tuhan) penulis". Abu Zayd juga mengkritik diskusi tradisional yang menyatakan bahwa al-Qur'an diturunkan serentak dari tablet Terjaga (al-Lawh al-mahfudz) dalam Bayt Al-Izzah ke langit Dunia (Sama' Al-Dunya). ${ }^{11}$

Abu Zayd mengatakan bahwa teks ketika turun kepada Nabi Muhammad berupa makna saja karena problem bahasa. Sehingga bagi Abu Zayd Nabi Muhammadlah yang membahasakannya kepada manusia. Sebagaimana yang diungkapkannya dalam bukunya Voice of an Exile, The "The word of Mubammad reporting what he asserts is the Word of God. This is the Qur'an". Dia juga menyatakan "The word of God needed to adapt itself become human, because God wanted to communicate to buman beings. If God spoke Godlanguage, buman beings would understand nothing". ${ }^{12}$ Menurut, Abu Zayd, Kalam Ilahi ${ }^{13}$ perlu mengadaptasi diri dan menjadi

${ }^{11}$ Moch Nur Ichwan, Meretas Keserjanaan Kritis Al-Qur'an, 71

12 Lihat: Nasr Hamid, Voice of an Exile:Reflection on Islam, 96-97. Dikutip dari Lalu Nurul Bayanil Huda, Konsep Teologi Nasr Hamid Abu Zayd Dan Implikasinya Terhadap Konsep Wahyu (Studi Kritis), Tesis tidak diterbitkan. (ISID,GONTOR. Ponorogo, 2010), 120

${ }^{13}$ Menurut Moch Nur Ikhwan, salah seorang murid Nasr Hamid, bahwa Nasr Hamid menggunakan distingsi Ferdinan De Saussure, seorang tokoh dikenal sebagai peletak dasar linguistic modern, yaitu tentang Parole (ucapan) dan Langue (bahasa), yang dia terjemahkan dalam bahasa Arab "kalam" dan "lugah" untuk membedakan antara "kode linguistik spesifik teks" dan "system linguistic budaya" di mana teks muncul. Langue adalah system bahasa sebagai keseluruhan yang sejatinya bersifat social dan independent dari individu tertentu; sementara parole adalah ucapan-ucapan atau tindak komunikasi individu. Hubungan antara langue dan parole bersifat dialektik, karena parole, meskipun mempunyai partikularitasnya sendiri, menguak struktur general system linguistic (langue). Bagi, Abu Zaid, bahasa al-Qur'an adalah parole dan 
manusiawi. Karena Tuhan ingin berkomunikasi dengan manusia. Jika Tuhan berbicara dengan bahasa Tuhan, manusia (Nabi) tidak akan mengerti. ${ }^{14}$ Dengan pemahaman seperti ini, mengindikasikan bahwa parole Allah yang ada di al-laub al-Mahfudz harus tunduk pada aturan-aturan langue Arab.

Atas dasar itulah Abu Zayd membuat proses pewahyuan (tanzil) melalui dua tahapan. Pertama, adalah tahap tanzil yaitu proses turunnya teks (Al-Qur'an) dari Allah swt kepada malaikat Jibril atau rubul amin. Pada taraf vertical (Allah-Jibril) teks masih berupa teks nonbahasa. Dalam tahap horizontal malaikat menyampaikan kepada Nabi Muhammad (manusia) yang kemudian disampaikan kepada umat manusia. Konsep "menurunkan/tanzil" di sini harus dipahami sebagai menurunkan kepada manusia melalui dua perantara: pertama, malaikat; dan kedua, adalah Muhammad yang berbentuk manusia. ${ }^{15}$ Dalam tahap ini ayat-ayat al-Qur'an masih berupa makna saja. Kedua, adalah proses takwil yaitu proses dimana Nabi Muhammad saw menyampaikan teks Al-Qur'an dengan bahasanya yaitu bahasa Arab. Dalam proses ini Nash Al-Qur'an berubah dari teks Ilahi

bahasa Arab adalah langue. Lihat: Moch Nur Ichwan, Meretas Keserjanaan Kritis, 74-75.

${ }^{14}$ Pandangan ini hampir sama dengan konsep hermes, tokoh dalam mitodelogi Yunani yang bertugas menjadi perantara antara dewa Zeus dan manusia. Hermes menyampaikan pesan dewa Zeus kepada manusia, menjelaskan bahasanya yang menggunakan bahasa langit agar bisa dimengerti oleh manusia yang menggunakan bahasa bumi. Lihat: Warner G. Jeanrond, The theological Hermeneutcs: Development and Significance, (New York: Crossroad, 1991), 1; pengasosiasian hermeneutika dengan hermes ini saja secara sekilas menunjukkan adanya tiga unsur vareabel utama pada kegiatan manusia dalam memahami, yaitu; Pertama, tanda, pesan atau teks yang menjadi sumber atau bahan dalam penafsiran yang diasosiasikan dengan pesan yang dibawa oleh Hermes. Kedua, Perantara atau penafsir (Hermes), Ketiga, Penyampaian pesan itu oleh sang perantara agar bisa dipahami dan sampai kepada yang menerima. Lihat, Fahruddin Faiz, Hermeneutika Al-Qur'an Tema-Tema Kontroversial, (Yogyakarta: eLSAQ, 2005), 4

15 Nasr Hamid, Tekstualitas Al-Qur'an Kritik Terhadap Ulumul Qur'an, Terjemah Khoiron Nahdliyyin (Yogyakarta: LKiS, 2003), 62. 
kepada teks Insani atau dari tanzil menjadi takwil. Pemahaman Muhammad atas teks merepresentasikan tahap paling awal dalam interaksi teks dengan akal manusia. ${ }^{16}$

Untuk merealisasikan tesisnya tersebut, Abu Zayd tampil cerdik menempatkan Nabi Muhammad sebagai penerima wahyu pada posisi sebagai “pengarang” al-Qur'an. Menurutnya dalam upaya menginterpretasikan pesan Tuhan dengan bahasanya, nabi tidak dalam keadaan kosong. Karena beliau adalah buah produk dari masyarakatnya. Ia tumbuh dan berkembang di Mekkah sebagai anak yatim, dididik dalam suku Bani Sa'ad sebagaimana anak-anak sebayanya di perkampungan Badui. Dengan demikian, Abu Zayd memandang bahwa Nabi Muhammad saw sebagai seorang ummy, bukanlah penerima pasif wahyu, tapi juga mengolah redaksi al-Qur'an sesuai dengan kondisinya sebagai manusia biasa. Sehingga dalam pandangannya al-Qur'an merupakan spirit wahyu yang disaring melalui Muhammad dan sekaligus diekspresikan dalam batas kemampuan linguistik beliau yang dipengaruhi oleh kondisi kejiwaan, sosial, dan budaya setempat. Konsep yang menyatakan bahwa teks al-Qur'an sebagai spirit wahyu dari Tuhan identik dengan konsep teks Bible, bahwa "The whole Bible is given by inspiration of God". ${ }^{17}$ Inilah yang menjadi dasar kemudian Abû Zayd menyimpulkan bahwa al-Qur'an adalah teks manusiawi (nash insani). ${ }^{18}$

Pandangan Abu Zayd ini kemudian diadopsi begitu saja oleh beberapa pemikir muslim Indonesia, disebutkan dalam sebuah buku berjudul Arah Baru Studi Ulum al-Qur'an: Menburu Pesan Tuban

16 Nasr Hamid mengatakan:" Al-nass mundhu lahZat nuzulibi al-ula-ayy ma'aqira'at al-Nabiyy lahu lahZat al-waby-tahawwala min kawnibi (nassan ilahiyyan) wa sara (nassan insaniyyan), liannabu tahawwala min al-tanzil ila al-ta'wil. Inna fabm alnabiyy yumatthil awla marabil harakat al-nas fi taha'ulibi bi al-'aql al-bashari." Lihat Nasr Hamid Abu Zaid, Naqd al-Kitab al-Dini (Kairo: Sina li al-Nashr, edisi pertama, 1992), 93; Lihat juga Nasr Hamid Abu Zayd, Kritik Wacana Agama, 98

${ }^{17}$ Adian Husaini dan Henri Salahudin, Studi Komparatif: Konsep al-Qur'an, 34.

${ }^{18}$ Nashr Hamid Abu Zaid, Kritik Wacana Agama, 98.

TAJDID Vol. 17, No. 2, Juli - Desember 2018 |159 
di Balik Fenomena Budaya, yang ditulis oleh Aksin Wijaya, ia menyatakan bahwa lancarnya penerimaan pesan Tuhan oleh masyarakat Arab tidak lain karena "Muhammad" membahasakan pesan Tuhan yang awalnya menggunakan bahasa non-ilmiah dalam bentuk parole Tuhan itu dengan sistem bahasa ilmiah yang digunakan masyarakat Arab sebagai audiens awal. ${ }^{19}$ Dia menyatakan dengan tegas bahwa Muhammad berperan besar dalam pemilihan bahasa ini. Dalam pandangan Aksin wahyu dalam konteks ini mulai mengalami "naturalisasi". Oleh karena itu, Pernyataan bahwa al-Qur'an yang diturunkan kepada Nabi Muhammad baik lafal dan maknanya sebagaimana yang dipahami oleh para ulama seperti Az-Zarqani, As-Suyuti, dan Manna' Kholil al-Khattan ditolaknya. Sebab, menurut Aksin perdebatan tentang apakah lafadz dan makna wahyu berasal dari Tuhan atau Muhammad yang menunjuk pada realitas supranatural dalam parole Tuhan atau di lawh al-Mahfudz, merupakan perdebatan yang tidak pada tempatnya, sebab hal itu wilayah supra-natural itu berada di luar jangkauan kapsitas akal manusia. ${ }^{20}$

Selain itu, dalam sebuah kata pengantar buku Metodelogi Studi Al-Qur'an, Dawam Raharjo juga mengemukakan hal yang sama. Menurutnya bahwa wahyu ketika turun kepada Nabi, ia bekerja dalam pemikiran Muhammad sehingga mengalami transformasi dari bahasa Tuhan ke bahasa manusia. Dan ketika wahyu itu disampaikan kepada sahabat, beberapa sahabat mentransformasikannya pula dalam bentuk transkip yang tunduk kepada hukum-hukum bahasa yang berlaku. ${ }^{21}$ Senada dengan itu, Ulil Absar Abdalla,dkk pada buku yang sama, mengatakan bahwa keterlibatan nabi Muhammad sebagai penerima pesan di satu sisi dan sebagai penafsir di sisi yang lain ikut menentukan proses

19 Lihat: Aksin Wijaya, Arah Baru Studi Ulum Al-Qur'an Memburu Pesan Tuban di Balik Fenomena Budaya, (Yogyakarta: Pustaka Pelajar, 2009), 86

${ }^{20}$ Aksin Wijaya, Arah Baru Studi Ulum Al-Qur'an, 87-89

21 Abd Moqsith Ghazali,dkk, Metodelogi Studi Al-Qur'an,(Jakarta: GEMA INSANI,2009), xviii

160 | TAJDID vol. 17, No. 2, Juli - Desember 2018 
pengujaran dan tekstualisasi al-Qur'an. Menurutnya, Muhammad bukan sebuah disket, melainkan orang yang cerdas, maka tatkala menerima wahyu Muhammad ikut aktif memahami dan kemudian mengungkapkannya dalam bahasa Arabnya sendiri. ${ }^{22}$

Pandangan Abu Zayd dan para pemikir liberal lainnya, tampaknya dapat dicari justifikasinya dari apa yang telah dilontarkan oleh sarjana Barat jauh sebelumnya. W. Mongtgomery Watt (1909-2006) dengan menggunakan pendekatan historisisme mengatakan wahyu al-Qur'an bersumber dari Tuhan tetapi diproduksi melalui pribadi Muhammad dalam konteks lingkungan dan sosio-religius (Yahudi-Kristen). Sintesis yang dilakukan oleh Watt tentang sumber wahyu dengan merujuk pada teori alam bawah sadar kolektif (collective unconsciousness) dari Carl Gustav Jung. Alam bawah sadar adalah tumpukan pengalaman masa lalu yang mengkristal, semakin lama semakin menjadi universal kemudian melebur ke dalam mental dan materialistis tubuh. Dalam bawah alam sadar kolektif muncul ide-ide keagamaan, ${ }^{23}$ yang oleh Watt dimaknai sebagai wahyu. ${ }^{24}$ Dengan menggunakan teori Gustaf Jung tersebut, Watt menolak malaikat Jibril sebagai pembawa wahyu. Wahyu hanya dalam bentuk makna, bukan dengan lafal. ${ }^{25}$ Karena ada peranan Nabi Muhammad dalam subtansi wahyu, Menurut Watt, memungkinkan terjadi kekeliruan dalam Al-Qur'an adalah "ajaran" (lesson, teaching)-nya, materinya diambil Nabi Muhammad dari lingkungannya. ${ }^{26}$

22 Abd Moqsith Ghazali,dkk, Metodelogi Studi Al-Qur'an,143

23 Carl Gustav Jung, Psycology and Religion (New Haven, Yale University Press, 1988), 5

${ }^{24}$ Mohammad Arkoun,dkk. Editor (May Rachmawatie and Yudhie R Haryono), Al-Qur'an Dimata Barat: Sebuah Studi Evaluatif," Al-Qur'an Buku Yang Menyesatkan dan Buku Yang Mencerabkan, (Bekasi: Gugus Press, 2002), 93

25 W. Montgomery Watt, Mubammad at Mecca: History in the Qur'an (Edinburgh at the Unversity Press, 1988), 63.

26 Mohammad Arkoun,dkk. Editor (May Rachmawatie and Yudhie R Haryono), Al-Qur'an Dimata Barat. 94

TAJDID Vol. 17, No. 2, Juli - Desember 2018 |161 


\section{Implikasi Konsep Tanzil Nasr Hamid Abu Zayd Terhadap Status Al-Qur'an}

Pandangan Abu Zayd tentang konsep tanzil di mana teks Ilahi (devine text) berubah menjadi teks manusiawi (buman text) sejak turunnya wahyu yang pertama kali kepada Nabi Muhammad,membawa konsekuensi logis yaitu menurunkan nilai sakralitas al-Qur'an sebagai firman Allah. Dengan berpandangan seperti itu, Abu Zayd menegaskan bahwa penekanan yang terlalu berlebihan pada (dimensi Ilahi) menjadikan pemikiran menjadi stagnan. ${ }^{27}$ Padahal dalam keyakinannya al-Qur'an adalah kata Muhammad yang meriwayatkan apa yang beliau katakan adalah kalam Ilahi. Karena statusnya tidak lagi bersifat transenden melainkan relatif yang bercampur dengan unsur-unsur kemanusiaan dan menjadi teks manusiawi yang bersandar pada kerangka kebudayaan yang terbatas. Atas dasar ini, kemudian Abu Zayd menyatakan al-Qur'an adalah produk budaya (muntaj thasaqafi). Asumsi dasarnya, al-Qur'an terbentuk dalam realitas budaya dalam jangka waktu lebih dari 20 tahun, mengekpresikan hubungan dialektika antara teks, budaya, dan realitas dalam sebuah momen historis tertentu. Fase selanjutnya ialah fase "pembentukan", di mana al-Qur'an membentuk suatu budaya baru sehingga al-Qur'an dengan sendirinya menjadi "produsen budaya" (muntij li al-thaqafi) karena ia menjadi rujukan bagi teksteks lainnya dalam budaya. ${ }^{28}$ Disebabkan realitas dan budaya tidak bisa dipisahkan dari bahasa manusia, maka Abu Zayd juga menganggap al-Qur'an sebagai teks bahasa (nas lughawi2)

Singkatnya, asumsi Abu Zayd baik menjadikan al-Qur'an sebagai teks manusiawi, produk budaya, produsen budaya dan teks bahasa sekaligus telah menjadikan status al-Qur'an sama seperti teks-teks profan lainnya dalam budaya. Pandangan tersebut secara

\footnotetext{
${ }^{27}$ Nasr Hamid Abu Zayd and Esther R. Nelson, Voice of an Exile., 57

${ }^{28}$ Nasr Hamid Abu Zayd, Mafbum al-Nas, 24

${ }^{29}$ Nasr Hamid Abu Zayd, Mafbum al-Nas, 10:18.
} 
eksplisit membawanya kepada sebuah kesimpulan yang parallel dengan Arkoun yaitu teks yang mutlak dan suci (dalam hal ini alQur'an), hanyalah yang berada di lawh al-Mahfudz, yang ada dalam keharibaan Tuhan dan tidak pernah diketahui oleh seorang muslim pun, melainkan dalam bentuknya yang sekarang. Pandangan tersebut pada akhirnya hanya menyisakan kenisbian dan meragukan kedudukan teks suci (agama) yang ada. Tentang poin ini, Abu Zayd kembali menjelaskan,".....bahwa kedudukan teks yang mentah dan sakral adalah bentuk metafisisnya yang tidak kita ketahui sedikit pun tentangnya. ${ }^{30}$

Dengan mencermati perkembangan yang terjadi pada studi Bibel, dapat disimpulkan bahwa Abu Zayd telah terpengaruh dengan metode historis yang telah diaplikasikan oleh cendekiawan Kristen terhadap kitab sucinya. Kenyataan ini bisa dilihat dari asumsi historisitas al-Qur'an yang dikemukakannya, baik dengan menyebutnya sekedar teks linguistic, produk budaya maupun teks manusia, tidaklah mempunyai dasar yang kuat. Sebab kesadaran ilmiah (al-wa'yu 1-ilmi) yang diproyeksikan Abu Zayd sebagai pendekatan ilmiah dalam kajian keagamaan, tidak lain adalah karbon kopi dari metode "kesadaran historis" (bistorical consciousness) versi Wilhem Dilthey ${ }^{31}$ dan tentunya bila diterapkan pada wacana keagamaan akan membawa konsekuensi pada relativasasi (meragukan) nilai-nilai agama dan mengedepankan realitas untuk berkuasa atas pemaknaan teks. ${ }^{32}$ Selain menyamakan status al-Qur'an dengan teks-teks yang lain, maka Nasr Hamid juga menegaskan siapa saja bisa mengkaji al-Qur'an. Nasr Hamid menyatakan: "saya mengkaji al-Qur'an sebagai sebuah teks berbahasa Arab agar dapat dikaji oleh kaum Muslim, Kristen,

${ }^{30}$ Nasr Hamid Abu Zayd, Kritik. Wacana Agama, 98

${ }^{31}$ Historical consciousness versi Willhem Dilthey adalab awareness of the relativity of all historical reality and phenomena, leads to the interpreter becoming critical of himself (bis situatedness) and striving for objective knowledge.Lihat: Hendri Salahuddin, Al-Qur'an Dibujat, 122

${ }^{32}$ Nasr Hamid Abu Zayd, Kritik W Wana Agama, 122

TAJDID Vol. 17, No. 2, Juli - Desember $2018 \mid 163$ 
maupun Ateis." ${ }^{33}$ seperti pengalaman hermeneut Barat dalam menyikapi Kitab suci mereka. Misalnya, Scheiermacher yang dikenal sebagai bapak hermeneutika modern, secara tegas mengemukakan sepatutnya buku-buku yang ada dalam Bibel diperlakukan sama dengan karya-karya tulis yang lain. ${ }^{34}$ sekalipun Bibel adalah wahyu, namun ia ditulis dalam bahasa manusia. ${ }^{35}$

Oleh karena itu, pengalaman sarjana Barat itulah kemudian diadopsi oleh Abu Zayd. hasilnya jelas seperti dikemukakan di atas mendudukkan Al-Qur'an tidak lagi sebagai kitab yang bernilai suci melainkan sebagai teks profan atau nisbi. Dengan menyamakan alQur'an setara dengan teks-teks lain, berarti Abu Zayd telah membebaskan bagi siapa saja untuk mengkajinya. Akarnya jelas bisa dilacak dari penerapan metodelogi hermeneutika yang sangat berpotensi untuk menyamarkan kedudukan teks-teks suci agama. ${ }^{36}$

\section{7}

${ }^{33}$ Dikutip dari Moch. Nur Ichwan, Meretas Keserjanaan Kritis Al-Qur'an, 66-

34 Menurut Schleimacher, Surat Timotius yang pertama bukan berasal dari Paulus, penggunaan bahasa serta situasi yang digambarkan di dalam teks tersebut, tidak sesuai dengan kehidupan Paulus. Lihat Werner Georg Kummel, The New Testament: The History of the Investigation of its Problems, Pen. S. McLean Gilmour dan Howard C. Kee (Tennessee: Abingdon Press, 1972), 84

35 Aref Ali Nayed, Interpretation as the Engagement of Operational Hermeneutics (Desertasi Doktoral di Universitas Guelph, 1994), 3; Dikutip dari Adnin Armas, Filsafat Hermeneutika dan Dampaknya Terhadap Studi al-Qur'an, INSISTS, Kumpulan Makalah Peneliti Insists,2010, 5

36 Watak dasar hermeneutika yang dikembangkan oleh kultur Barat dan pengalaman historis yang tidak sejalan dengan Islam. ketidak sesuaian itu bisa dilihat dari beberapa unsur berikut; pertama: hermeneutika secara jelas menyamarkan kedudukan teks-teks suci agama; karena memang pada awalnya hermeneutika ditujukan untuk menjembatani kewibawaan dan keaslian teks Bibel yang bermasalah. Kedua, penentuan kontekstual terhadap makna dengan mengesampingkan kemapanan bahasa dan susunan makna dalam bahasa (semantic structures), menyebabkan kosa kata dalam teks kitab suci selalu permisif untuk disususpi berabagai dugaan (guess/conjecture), pembacaan subjektif dan pemahaman yang hanya mendasarkan pada relativitas sejarah. Ketiga, memisahkan makna antara yang normatif dan yang historis di satu sisi dan menempatkan kebenaran (truth) secara kondisional menurut kultur tertentu suasana historis di sisi lain, akan cenderung pada paham sekuler. Lihat:Bin Shafie, Ahmad Bazli, 2004, A Modernist Approach to the Qur'an: A Critical Study of 
Oleh karena itu, klaim historisitas al-Qur'an adalah salah satu contoh bagaimana hermeneutika mempengaruhi alam pemikiran Abu Zayd. ${ }^{37}$

Meski demikian, pemahaman yang relatif terhadap al-Qur'an dengan menjadikannya sebagai produk budaya juga diperkuat oleh Fahruddin Faiz, dalam sebuah bukunya "Hermeneutika AlQur'an". Faiz melakukan periodeisasi mengenai kedudukan alQur'an. Tegasnya, Faiz mengatakan pada dataran mana al-Qur'an sebagai "produk budaya" dan pada dataran mana ia merupakan "produk Tuhan" ? atas dasar ini ia membagi al-Qur'an pada empat level; Level pertama, al-Qur'an berupa kalam Allah murni belum diwahyukan. Level kedua, ketika al-Qur'an diwahyukan secara verbatim oleh Allah kepada Muhammad dan untuk selanjutnya Muhammad menyampaikannya juga secara verbatim kepada ummatnya. Level ketiga, ketika Muhammad, generasi awal yang dilanjutkan dengan generasi-generasi selanjutnya memahami dan mengaplikasikan nilai-nilai ajaran Al-Qur'an dalam praksis nyata kehidupan. Level keempat, ketika al-Qur'an mewujud dalam sebentuk naskah tertulis dalam bahasa Arab yang dikodifikasi, diperbanyak dengan kertas dan tinta; lalu dibaca dan dipahami oleh Ummat Islam seluruh dunia. ${ }^{38}$

Singkatnya, dari keempat kategorisasi di atas, Faiz menilai alQur'an pada level ketiga dan keempat tidak lagi menyandang nilai sakral sebagaimana al-Qur'an yang sakral. Baginya yang sacral hanyalah kalam Allah yang ada di laub al-Mahfudr, sementara al-

the Hermeneutics of Fąlur Rahman, (A Thesis sutmitted in partial fulfillment of requirement for the degree of doctor of philosophy in Islamic thought), International Institute of Islamic Thought and Civilization (ISTAC), International Islamic University Malaysia (IIUM), belum dipublikasikan, 238. dikutip dari Hendri Salahuddin, Al-Qur'an Dibujat, Jakarta:AL QALAM,2007),125

${ }^{37}$ Hendri Salahuddin, Al-Qur'an Dibujat, 122

38 Fahruddin faiz, Hermeneutika Al-Qur'an, (Yogyakarta: eLSAQ, 2005),103-106

${ }^{38}$ Fahruddin faiz, Hermeneutika Al-Qur'an, 106

TAJDID Vol. 17, No. 2, Juli - Desember $2018 \mid 165$ 
Qur'an dalam bentuk Mushaf (Mushaf Usmani) yang dikodifikasi dan diterbitkan melalui kertas dan tinta, maka ekspresi perilaku dan hasil terbitan al-Qur'an tersebut adalah produk budaya. ${ }^{39}$ Implikasi ide semacam ini lagi-lagi merelatifkan keyakinan ummat Islam tentang hakekat al-Qur'an. hasil kongkritnya, banyak orang yang mulai meragukan al-Qur'an sebagai kalam Allah. bahkan, tindakan seperti menginjak asma Allah, melempar mushaf alQur'an ke lantai di depan kelas, dan mempersoalkan otentisitas alQur'an sudah mulai di kampus-kampus Islam. ${ }^{40}$

Kritik Terhadap Dekonstruksi Konsep Tanzil Nasr Hamid Abu Zayd

Penolakan Nasr Hamid tentang turunnya al-Qur'an secara sekaligus dari suatu tempat ke tempat yang lain yaitu dari dari tablet Terjaga (al-Lawh al-mahfudz) dalam Bayt Al-Izzah ke langit Dunia (Sama' Al-Dunya) tidaklah benar bahkan hipotesis semacam ini bertentangan Pandangan az-Zarqani yang juga didukung oleh kebanyakan ulama. Ibnu Katsir, ${ }^{41}$ al-Qurthubi, ${ }^{42}$ as-Syaukani, ${ }^{43}$ Fahrudin ar-Razi, ${ }^{44}$ dan yang lainnya juga memiliki pendapat yang sama dengan az-Zarqani, bahwa sebelum al-Qur'an disampaikan kepada Nabi Muhammad, ia diturunkan sekaligus ke langit dunia, yaitu bait al'izzah pada malam al-qadar. ${ }^{45}$ Artinya, pada tahap ini alQur'an masih belum terjadi proses tanzil dari malaikat kepada Nabi. Sumbernya adalah riwayat dari Ibn Abbas r.a. beliau berkata: "Allah menurunkan al-Qur'an sekaligus (dari al-lauh al-makhfud), dan meletakekanny di bait al-'izzah di langit dunia baru kemudian diturunkan oleh Mmalaikat Jibril kepada Nabi Mubammad saw untuk menjawab

${ }^{39}$ Fahruddin faiz, Hermeneutika Al-Qur'an, 106

${ }^{40}$ Hamid Fahmy Zarkasy, Liberalisasi Pemikiran Islam, 103

41 Lihat Ibn Katsir, Tafsir al-Qur'an al-'Adzim, Juz I, (Daar Thayyibah, 1999), hal 105.

${ }^{42}$ Lihat al-Qurthubi, Tafsir al-Qurthubi, Juz II, (tp, tt), 297.

${ }^{43}$ Lihat as-Syaukani, Fath al-Qadir, Juz I, (tp, tt), 240.

${ }^{44}$ Lihat Fahrudin ar-Razi, Mafatih al-Ghaib, Juz 17, (tp, tt), 125.

${ }^{45}$ Q.S. Al-Qadr ayat:1; Q.S. Al-Baqarah: 185

166 | TAJDID Vol. 17, No. 2, Juli - Desember 2018 
perkataan manusia dan segala amalnya". 46 Dalam riwayat yang lain Ibnu Abbas r.a. berkata: "Qur'an diturunkan sekaligus pada malam lailatul qadar pada bulan Ramadhan ke langit dunia sekaligus; lalu ia diturunkan secara beransur-ansur". ${ }^{47}$

Selain itu, konsep tanzil al-Qur'an yang digagas oleh Abu Zayd dan pemikir muslim lainnya seperti disebutkan di atas, jelasjelas telah membongkar konsep dasar tentang Al-Qur'an yang selama ini diyakini kaum Muslimin, bahwa al-Qur'an, baik lafadz maupun makna-nya adalah dari Allah. Sebagaimana pendapat umumnya dipegang oleh beberapa ulama yang pakar dalam ilmu al-Qur'an, Seperti Muhammad 'Abd al-Adzim Az-Zarqani, yang menjelaskan bahwa yang dibawa malaikat Jibril adalah Al-Qur'an, yang berupa lafadz-lafadz dalam artian hakiki, mulai dari surah alFatihah hingga surah al-Nas. Dan lafadz-lafadz tersebut adalah Kalam Allah swt sendiri yang tidak terkontaminasi oleh perkataan Malaikat atau Nabi Muhammad saw. dialah Allah yang menyususn sendiri lafadz-lafadz al-Qur'an. ${ }^{48}$ Jalaluddin As-Suyuti as- Syafi'i juga mengatakan hal serupa bahwa apa yang diterima Nabi dari wahyu melalui malaikat Jibril adalah apa-apa yang telah diterimanya dari Allah apa adanya, tanpa ada perubahan sedikit pun. Menurutnya, hal ini sama dengan raja telah menulis surat, kemudian menyerahkannya kepada orang kepercayaanya. ${ }^{49}$ Dalam sebuah kitabnya "Mabahits fi Ulum al-Qur'an”, Manna' Khalil alKhattan juga memiliki pandangan yang sama dengan ulama lainnya bahwa al-Qur'an merupakan merupakan kalam Allah, baik lafadz dan maknya. ${ }^{50}$ Inilah yang menurut Prof.Dr. A. Athaillah,

46 Lihat at-Thabrani, Mu'jam al-Kabir, Juz. 12,(Maktabah al-'Ulum wa alHikam, 1983), hal 32.

${ }^{47}$ Hadits Tabarani. Dikutip dari Manna Khalil Al-Khattan, 147

48 Muhammad 'Abd al-Adzim az-Zarqani, Manabil al-Irfan fi Ulum alQur'an (Beirut: Dar al-Kitab al-Arabi, 1995),43-44

${ }^{49}$ Jalaluddin As-Suyuti as- Syafi'i, Al-Itqan Fi Ulum al-Qur'an, (Beirut: Darul fikr, 2005),Juz 1. 6;

${ }^{50}$ Manna' Khalil al-Qattan, Studi Ilmu-ilmu Qur'an, Terj: Mudzakir AS (Bogor: Pustaka Lentera AntarNusa, 2007),27

TAJDID Vol. 17, No. 2, Juli - Desember $2018 \mid 167$ 
ketika mendasari pandangannya pada konsiderat ayat: "Dan sesunggubnya al-Qur'an ini benar-benar diturunkan oleh Tuban semesta alam, dia dibawa turun oleh al-Ruh al-Amin (Jibril) ke dalam hatimu (Muhammad) agar kamu menjadi salah seorang di antara orang-orang yang member peringatan dengan bahasa Arab yang jelas." membuktikan bahwa Nabi Muhammad saw telah menerima alQur'an itu benar-benar dalam bentuk makna dan lafalnya, tanpa ada campur tangan dan interpretasi Jibril atau Muhammad saw. ${ }^{52}$ bahkan Prof. Dr. Quraish Shihab dalam "Tafsir al-Misbahnya", ketika menginterpretasikan ayat di atas, berpandangan bahwa bila wahyu (al-Qur'an) turun, beliau mengalami suatu keadaan yang sangat berat, mirip dengan seorang yang tidak sadarkan diri, walau beliau sepenuhnya sadar. Dan dengan demikian, ia sangat murni, tidak disertai dengan campur tangan atau interpretasi dari apa dan siapa pun. Menurutnya, ini juga berarti bahwa beliau menerima wahyu Ilahi itu dengan lafadz dan maknanya, tegasnya, kalaulah nabi Muhammad hanya menerima maknanya saja, tentu ada keterlibatan nalar untuk menyusun makna itu dalam bentuk katakata. ${ }^{53}$ Untuk itu wahyu tidak bisa dipandang sebagai sebuah teks seperti klaim Nasr Hamid, Namun sebagai sebuah wahyu yang turun dalam bentuk lafadz dan makna. Sebagaimana disampaikan Prof.Dr. Syaich Mahmoud Sjaltout, bahwa dalam memberi definisi al-Qur'an tidak boleh terlepas dari unsur-unsur dan pokok-pokok dari al-qur'an itu sendiri yaitu kedudukannya sebagai lafadz (bukan teks), kedudukannya berbahasa Arab, kedudukannya yang diturunkan kepada nabi Muhammad saw dan terakhir disampaikan kepada ummat secara mutawatir. ${ }^{54}$ Oleh karena itu, adanya kesamaan konsepsi semacam itu menunjukkan bahwa struktur

51 Q.S.al-Syu'ara:192-195

52 A. Athaillah, Sejarah Al-Qur'an Verivikasi Tentang Otentisitas Al-Qur'an, (Yogyakarta: Pustaka Pelajar, 2010),119

53 M. Quraish Shihab, Tafsir Al-Misbah, (Jakarta: Lentera Hati, 2002), cetakan 1, volume 9, 339-340

54 Syaich Mahmoud Sjaltout, Islam Sebagai Aqidab dan Syari'ah, terj. Jilid V, (Jakarta: Bulan Bintang, 1970), cetakan pertama, 12

168 | TAJDID Vol. 17, No. 2, Juli - Desember 2018 
konseptual yang jelas dalam Islam yang membedakan antara alQur'an dan Hadits.

Dalam konsepsi Islam, Nabi Muhammad saw tidak mengolah atau mengapresiasi wahyu yang diterimanya, untuk kemudian disampaikan kepada ummatnya. Posisi beliau dalam menerima dan menyampaikan wahyu memang pasif hanya sebagai penyampai apa-apa yang diwahyukan kepadanya. Beliau tidak menambah atau mengurangi apa yang disampaikan Allah melalui malaikat Jibril. Beliau terjaga dari segala kesalahan, karena beliau ma'sum. ${ }^{55}$ Meskipun firman Allah itu menggunakan penuturan nabi, namun penuturan itu tidak menyimpang sedikitpun dari firman Allah yang disampaikan kepada Nabi. Oleh karena itu, inilah yang dimaksud bahwa al-Qur'an adalah firman Allah yang diucapkan Nabi, namun yang diucapkan itu bukan menurut kemauan hawa nafsunya. ${ }^{56}$ "Dan dia (Mubammad saw) tidak menyampaikan sesuatu, kecuali dari wabyu yang diwabyukan kepadanya. ${ }^{, 57}$ Sebaliknya, selain tidak ada kemungkinan dan izin untuk memasukkan imajinasi Nabi kedalam wahyu, tidak boleh juga nabi mengada-ngada sesuatu yang tidak terdapat dalam wahyu. "Tika seandainya dia (Mubammad) mengadangada sebagian perkataan (aqawil) atas nama kami, niscaya benar-benar kami pegang dia pada tangan kanannya, kemudian benar Kami potong urat tali jantungnya. Maka sekali-kali tidake ada seorang pun dari kamu yang dapat menghalangi (Kami) dari pemotongan urat nadi itu. ${ }^{58}$ Nampaknya itu yang dimaksud oleh Prof.Dr.Muhammad Nuqaib al-Attas, dengan tidak bercampur dengan muatan subjektivitas dan imajinasi kognitif Nabi. ${ }^{59}$ Tegasnya, jika al-Qur'an bukan dari sisi Allah baik lafadz dan maknya, maka akan terjadi pertentangan. 34

55 Adian Husaini dan Hendri Salahuddin, Studi Komperatif:Konsep Al-Qur'an,.

56 Hamid Fahmy Zarkasyi, Mengidentifikasi Teori Liberalisasi, Majalah Islamia, Volume. VI, No.1,2012. 8

${ }^{57}$ Surat al-Najm: 3

${ }^{58}$ Q.S. al-Najm:44-47

${ }^{59}$ Muhammad Naquib al-Attas, Prolegomena To The Metaphysics of Islam, (Kuala Lumpur, Malaisia: Prospecta, 1995), 6

TAJDID vol. 17, No. 2, Juli - Desember 2018 | 169 
Seperti terdapat dalam Al-Qur'an, "Maka tidakekah mereka menghayati (mendalami) al-Qur'an? sekiranya al-Qur'an itu bukan dari Allah, pastilah mereka menemukan banyak, bal yang bertentangan di dalammya. ${ }^{60}$

Selain dari beberapa alasan di atas, argumentasi lainnya adalah jika al-Qur'an adalah kata-kata (takwil) nabi terhadap firman Allah seperti asumsi Nasr Hamid dan pemikir muslim lainnya, mengapa malaikat Jibril perlu membacakan ulang al-Qur'an itu kepada Nabi setahun sekali seperti hadits yang diriwayatkan dari Fatimah ${ }^{61}$ dan Ibn Abbas. ${ }^{62}$ Apakah nabi lupa tentang takwilnya sendiri terhadap firman Allah itu. Selain itu, Jika al-Qur'an adalah takwil Nabi, masalahnya jika demikian apa bedanya al-Qur'an dengan hadits Qudsi atau hadits Saheh yang gaya bahasanya tidak menuntut untuk ditantang dan membacanya pun tidak dianggap ibadah. ${ }^{63}$ Selain itu, al-Qur'an bukanlah teks manusiawi sebagaimana klaim Nasr Hamid. al-Qur'an adalah nash Ilahi Kemudian, Jika alQur'an adalah bahasa nabi atau kata-kata nabi, seharusnya nabi

${ }^{60}$ Surat An-Nisa':82

${ }^{61}$ Diriwayatkan Fatimah, ia mengatakan "Nabi Muhammad memberitabukan kepadaku secara rahasia, Malaikat Jibril hadir membacakan Al-Qur'an padaku dan saya membacakannya sekali setabun. Hanya tabun ini ia membacakan selurub isi kandungan Al-Qur'an selama dua kali. Saya tidake berfikir lain kecuali, rasanya, masa kematian sudah semakin dekat." Lihat: Al-Bukhari, Sabih, Bab Fada'il Al-Qur'an,:7. dikutip dari M.M.Al-A'zami, The History of The Qur'anic Text From Revelation to Compilation: A Comperative Study With the Old and New Testaments, (Jakarta: Gema Insani, 2005), 55

62 Diriwayatkan Ibn 'Abbas melaporkan bahwa Nabi Muhammad berjumpa dengan Malaikat Jibril setiap malam selama bulan Ramadan hingga akhir bulan, masing-masing membaca al-Qur'an silih berganti. Lihat: AlBukhari, Sahih, Bab Saum:7; Ibid., 55

${ }^{63}$ Hadits kudsi ialah hadis yang oleh Nabi saw disandarkan kepada Allah. Maksudnya Nabi meriwayatkannya bahwa itu adalah kalam Allah. Maka rasul menjadi perawi kalam Allah ini dengan lafal dari Nabi sendiri. Manna alKhattan menegaskan bahwa Hadits Qutsi ialah maknanya dari Allah, ia disampaikan kepada Rasulullah s.aw inilah pendapat yang kuatdinisbahkannya hadits kudsi kepada Allah swt adalah nisbah mengenai isinya, bukan nisbah mengenai lafalnya. Sebab seandainya hadits Qutsi itu lafalnya juga dari Allah, maka tidak ada lagi perbedaan antara hadits kudsi dengan al-Qur'a; dan tentu pula gaya bahasanya menuntut untuk ditantang, serta membacanyapun dianggap ibadah. Lihat: Manna' Khalil al-Qattan, Studi Ilmu-Ilmu Al-Qur'an, 227-29 
Muhammad mengerti tentang al-ahruf al-Muqatta'ah ن, بس ,كيعص, الم, dan lain-lain, tetapi faktanya jika al-Qur'an merupakan katakata beliau, maka dengan sendirinya beliau akan mengerti hurufhuruf tersebut. Alasan lainnya ialah Jika al-Qur'an adalah kata-kata Nabi yang menyesuaikan diri dengan budaya dan masyarakat setempat. kenapa dalam ayat al-Qur'an berisi teguran terhadap sikap nabi Muhammad saw, "Dan janganlah kamu melaksanakan shalat (jenazah) seseorang yang telah mati di antara mereka dan janganlah (pula) kamu berdiri di atas kuburnya. Sesunggubnya mereka telah kufur terbadap Allab dan Rasul-Nya dan mereka telah (pula) mati dalam keadaan fasik." ${ }^{\text {64 }}$ Kemudian jika al-Qur'an adalah takwil nabi, mengapa nabi mendapat peringatan untuk tidak tergesa-gesa menghafal al-Qur'an "Janganlah kamu gerakekan lidahmu untuk (membaca) al-Qur'an karena hendak cepat-cepat (menguasainya).

${ }^{64}$ Surat at-Taubah: 84; adapun asbabun nuzul ayat ini ialah berawal ketika Ibn Abbas telah menceritakan bahwa ketika Abdullah ibn Ubay ibn Salul sakit keras, Rasulullah saw dating menjenguknya. Ia kemudian memohon kepada Rasulullah saw agar berkenan melaksanakan shalat bagi jenazahnya apabila ia meninggal, berdiri di atas kuburnya, dan memohon baju beliau untuk menjadi kafannya. Rasulullah saw kemudian mengirimkan baju beliau bagian atas. Namu, baju itu dikembalikannya dan ia memohon lagi baju yang dapat melindungi kulitnya untuk menjadi kafannya. Umar bertanya kepada Rasulullah saw, "Kenapa tuan memberikan baju tuan untuk orang yang kotor dan bernajis ini?" Rasulullah bersabda, "Bajuku itu tidak bermanfaat sedikit pun untuknya dihadapan Allah, namun aku berharap, semoga dengan itu Allah akan menggerakkan seribu orang dari kalangan munafik untuk memeluk Islam. Pada waktu itu orang-orang munafik banyak yang mendampingi Abdullah. Ketika mereka melihat pemimpin mereka itu memohon baju tersebut dan mengharapkan agar bermanfaat padanya, pada waktu itu juga seribu orang di antara mereka memeluk Islam. Setelah Abdullah meninggal, putranya mendatangi Rasulullah untuk memeberi tahukannya. Rasulullah saw bersabda kepada putra Abdullah, yang juga bernama Abdullah, "Shalatkan dan kafani jenazahnya." Abdullah memelas, "Kalau tuan tidak mau melaksanakan shalat jenazahnya, tidak ada seorang muslim pun wahai Rasulullah yang bersedia melaksanakan shalat jenazahnya." Rasulullah kemudian berdiri untuk melaksanakannya, namun Umar juga di antara beliau dan arah kiblat agar beliau tidak dapat melaksanakan shalat jenazah pemimpin orang-orang munafik itu. Kemudian turun ayat tersebut yang menegur tindakan beliau tersebut. Lihat: Fakhr al-Din al-Razi, Mafatih al-Ghaib, Jld. VI, Dar al-Fikr, Beirut, Cet. Pertama, $1425 \mathrm{H} / 2005 \mathrm{M}, 3393$ 
Sesungguhnya atas tanggungan Kami mengumpulkannya (didadamu) dan (membuatmu pandai) membacanya. Apabila Kami telab selesai membacakannya maka ikutilah bacaan itu. Kemudian, sesunggubnya atas tanggungan Kamilah penjelasannya. ${ }^{* 55}$ Oleh karena itu, problem bahasa yang dianggap alasan menurunkan makna al-Qur'an kepada nabi Muhammad saja tidak tepat. Sebab Allah dengan sangat jelas menceritakan komunikasi verbalnya kepada nabi Musa, "Dan (Kami telah mengutus) rasul-rasul yang sungguh telah Kami kisabkan tentang mereka kepadamu dabulu, dan rasul-rasul yang tidak Kami kisabkan tentang mereka kepadamu. Dan Allah telah berbicara kepada Musa dengan langsung. ${ }^{\circ 66}$

Dari beberapa analisis di atas, menunjukkan bahwa akar dari kerancuan konsep tanzil Nasr Hamid yang membedakannya dengan kalangan ulama dan mufassir seperti dalam analisisnya Dr. Hamid Fahmy Zarkasyi, ialah disebabkan oleh pengaruh dari luar tradisi intelektual Islam. Akarnya bisa dilacak dari konsepsinya tentang Tuhan yang masih tidak terlepas dari konsep Tuhan para filsof. Di dalam pemikiran filsafat Barat Tuhan digambarkan sebagai zat yang sangat transcendent yang tidak terjangkau oleh akal manusia. Karena Tuhan dianggap tidak mengetahui hal-hal yang particular, serta masuk kedalam ruang dan waktu. Maka baginya Tuhan tidak mungkin berbicara dalam bahasa manusia, karena jika demikian maka Tuhan akan menjadi particular dan tidak universal lagi. Artinya Tuhan tidak masuk dalam alam manusia yang relatif. Ini tentu bertentangan dengan konsep Tuhan dalam Islam yang transenden dan sekaligus imanen, bahkan lebih dekat dengan dari urat nadi hambanya. ${ }^{67}$ Selain itu, Tuhan

${ }^{65}$ Qur'an, 75: 16-19

66 Surat al-Nisa' :164: Adapun tafsiran ayatnya ialah Allah berbicara langsung dengan Nabi Musa a.s. merupakan keistimewaan Nabi Musa a.s., dan karena Nabi Musa a.s. disebut: Kalimullab sedang rasul-rasul yang lain mendapat wahyu dari Allah dengan perantaraan Jibril. Dalam pada itu Nabi Muhammad s.a.w. pernah berbicara secara langsung dengan Allah pada malam hari di waktu mi'raj.

${ }^{67}$ Hamid Fahmy Zarkasyi, Mengidentifikasi Teori Liberalisasi, 8 
transenden dipahami tidak memiliki aspek immanen atau sesuatu yang transenden dan metafisis tidak mungkin menjangkau ranah immanen menunjukkan bahwa Tuhan tidak lagi berkuasa atas segala ciptaan-NYa.

Selain itu, Kesimpulan Abu Zaid bahwa al-Qur'an adalah produk budaya, produsen budaya dan teks linguistik membawa pengertian bahwa al-Qur'an dihasilkan secara kolektif dari serangkaian factor politik, ekonomi, dan social. Atau dengan kata lain, al-Qur'an adalah hasil pengalaman individual yang diperoleh Nabi Muhammad dalam waktu dan tempat tertentu dimana latar belakang sejarah saat itu mengambil peranan inti dalam mewarnai pemikiran beliau dan bahasa sebagai perangkat ungkapan sejarah (expressional tool of history). ${ }^{68}$ Oleh karena itu, klaim Nasr Hamid AlQur'an sebagai produk budaya tidaklah tepat. karena al-Qur'an bukanlah hasil kesinambungan dari budaya yang ada. Al-Qur'an justru membawa budaya baru dengan menentang serta mengubah buadaya yang ada.hal ini terlihat ketika al-Qur'an diturunkan secara bertahap selama lebih dari dua puluh tahun, mendapatkan tentangan yang demikian dahsyat dari Arab Jahiiyyah saat itu. Dalam al-Qur'an diceritakan: "Mereka berkata: bagi orang-orang yang diturunkan al-Qur'an kepadanya, sesunggubnya kamu benar-benar orang gila" atau tuduhan sebagai penyair gila, ${ }^{69}$ juga sebagai tukang tenung. ${ }^{70}$ Al-Qur'an juga menentang budaya Jahiliyyah yang bangga dengan kemampuan puisinya,"katakanlah sesunggubnya jika manusia dan jin berkumpul dan membuat yang serupa al-Qur'an ini, niscaya mereka tidak akan dapat membuat yang serupa dengan dia, sekalipun mereka menjadi pembantu bagi sebagian yang lain."71 Ibn Ishaq (150 $\mathrm{H} / 767 \mathrm{M}$ ), seorang ahli tarikh, menyatakan orang-orang Quraisy menganggap al-Qur'an adalah sesuatu yang sangat asing dengan

\footnotetext{
${ }^{68}$ Hendri Salahuddin, Al-Qur'an Dibujat, 122-125

${ }^{69}$ Surat al-Saffat: 36

70 Surat al-Tur: 29

${ }^{71}$ Surat al-Isra':88
}

TAJDID Vol. 17, No. 2, Juli - Desember 2018 |173 
budaya mereka. ${ }^{72}$ Selain itu, al-Jahiz (w.869) dalam kitabnya “"Hujaj an-Nubuwwah" (bukti-bukti Kenabian) menyatakan bahwa para maestro sastra sezamannya tak mampu menandingi kualitas sastra al-Qur'an, padahal mereka sangat menentang Islam. ${ }^{73} \mathrm{Al}$-Qur'an bukanlah produk budaya karena sejak awal diturunkan dari lauh al-mahfudz ke sama'ul ardi sekaligus dan baru kemudian diturunkan ke dunia secara bertahap, ${ }^{74}$ dalam konteks ini Al-Qur'an tidak terkonstruk oleh budaya arab setempat.

Al-Qur'an juga bukan teks bahasa biasa seperti klaim Nasr Hamid, sebab jika al-Qur'an teks bahasa biasa, maka logikanya, Rasulullah saw. ahli di bidang tulisan dan bacaan, yang karena keahliannya itu bisa membawa perubahan sangat mendasar pada masyarakat Arab waktu itu. Padahal, Rasulullah saw. itu ummi. Jadi, sekalipun al-Qur'an disampaikan oleh Rasulullah saw kepada ummatnya pada abad ke-7 Masehi, namun ini tidak serta merta mengindikasikan bahwa al-Qur'an terbentuk dalam situasi dan budaya yang ada pada abad ke-7 Masehi. Al-Qur'an melampaui historisitasnya sendiri karena al-Qur'an dan ajarannya adalah transhistoris. Kebenarannya sepanjang zaman. ${ }^{75}$ Menurut al-Attas, al-Qur'an telah mengislamkan bahasa Arab pra-Islam, yaitu pada waktu itu masih mencerminkan pandangan dunia jahiliah, dengan cara menyusun dan membentuk kembali struktur konsep, bidangbidang semantic dan perbendaharaan katanya. Karena bahasa Arab yang dibawa oleh al-Qur'an adalah bahasa Arab bentuk baru. Sejumlah kosa-kata pada saat itu, telah diislamkan maknanya.alQur'an mengislamkan struktur-struktur konseptual, bidang-bidang semantic dan kosa-kata. Khususnya istilah-istilah dan konsepkonsep kunci, yang digunakan untuk memproyeksikan hal-hal

72 Adnin Armas, Metodelogi Bibel, 74.

${ }^{73}$ Abdur Rahman al-Bagdadi, Al-Qur'an Mukjizat yang Abadi, AL-INSAN Jurnal Kajian Islam, Edisi 1, Gema Insani, Januari 2005. 104

${ }^{74}$ Imam al-Zarkasyi dalam kitabnya al-Burban fi'Ulum al-Qur'an (Darul alturath, Kairo), 228.

${ }^{75}$ Imam al-Zarkasyi dalam kitabnya al-Burban fi'Ulum al-Qur'an, 77-78

174 | TAJDID Vol. 17, No. 2, Juli - Desember 2018 
yang bukan dari pandangan hidup Islam. ${ }^{76}$ beberapa contoh kongkrit yang dipaparkan oleh oleh al-Attas mengenai kata penghormatan (muruwwah), kemulyaan (karamah). Kedua kata tersebut adalah bagian dari sejumlah elemen penting dalam pandangan dunia kehidupan pra-Islam yang maknanya berhubungan erat dengan kepemilikan banyak anak, kekayaan dan karakter tertentu yang merefleksikan kelelakian. Al-qur'an mengubah makna tersebut dengan sangat mendasar dengan memperkenalkan factor kunci, ketakwaan (taqwa). Al-Qur'an menyebutkan: "Sesungguhnya yang paling mulia di sisi Tuhanmu adalah orang yang paling bertakwa." 77

Selain itu, al-Qur'an juga merubah semantik dasar dari kata karim. Kemuliaan disini diasosiasikan dengan al-Qur'an: Kitab Karim atau ucapan kepada orang tua dengan qaul karim. Padahal orang-orang Arab sebelum Islam tidak pernah menghubungkan kemuliaan dengan buku-buku, kata-kata (words or speech), sekalipun mereka sangat menghargai kemampuan pengarang dan membaca puisi. Contoh lain terjadi juga kepada kata persaudaraan (ikhwah), yang berkonotasi kekuatan dan kesombongan kesukuan, yang terkait dengan darah, dan tidak merujuk kepada makna lain. AlQur'an lagi-lagi mengubah ini dengan memperkenalkan gagasan persaudaraan yang dibangun atas dasar keimanan, yang lebih tinggi daripada persaudaraan darah. ${ }^{78}$ Jika lafą̧ $b$ dan bahasa al-Qur'an terpengaruh oleh sejarah dan sosial budaya Arab, maka bahasa alQur'an akan dengan mudah dipahami oleh orang Arab pada saat itu. Ternyata, bukan hanya saat itu saja, sekarang pun tak semua orang Arab bisa memahaminya. Tidak semua kata di dalam alQuran dapat dipahami sahabat. Abdullah ibn Mas'ud tidak tahu makna fathara. Pun, Abu Bakr dan Umar soal makna abb. Selain

76 Wan Mohd Nor Wan Daud, Filsafat dan Praktik Pendidikan Islam, Terj.Hamid Fahmy.dkk (Bandung: Mizan,2002), 341

77 Adnin Armas, Metodelogi Bibel,.75-76

${ }^{78}$ Wan Mohd Nor Wan Daud, Filsafat dan Praktik Pendidikan.., 342 
itu, wujud al-abruf al-muqata'ah di dalam al-Quran tidak sesuai dengan perkembangan sastra Arab saat itu. ${ }^{79}$

Oleh karena itu, dari beberapa dalih seperti disebutkan di atas menunjukkan bahwa konsep tanzil Nasr Hamid tidaklah tepat bahkan bertentangan dengan konsep yang ada dalam Islam. termasuk Pandangannya tentang ketidakmungkinan bahasa Tuhan dipahami oleh manusia hanyalah gagasan yang mengada-ngada (utopis). Demikian juga, ketika konsep teks al-Qur'an dibongkar dan dilepaskan dari posisinya sebagai kalam Allah, maka al-Qur'an akan diperlakukan sebagai teks bahasa dan produk budaya, sehingga bisa dipahami melalui kajian historisitas, tanpa memperhatikan bagaimana Rasulullah dan para sahabat beliau mengartikan atau mengaplikasikan makna ayat-ayat al-Qur'an dalam kehidupan mereka. Dengan pembongkaran konsep alQur'an sebagai kalam Allah ini, maka barulah metode hermeneutika liberal memungkinkan digunakan untuk memahami al-Qur'an. metode ini memungkinkan penafsiran al-Qur'an menjadi bias dan disesuaikan dengan tuntutan nilai-nilai budaya yang sedang dominan (Barat). ${ }^{80}$

\section{Kesimpulan}

Dari uraian di atas jelas bahwa problem yang paling mendasar dari kesalahan konsep tanzil Nasr Hamid adalah implikasi dari keberadaan Tuhan yang dipahaminya. Dalam pandangannya Tuhan tidak bisa berkomunikasi langsung dengan Nabi Muhammad, karena problem bahasa sehingga apa yang diterima Nabi hanyalah wahyu dalam bentuk makna atau ide. Akarnya jelas tidak terlepas konsepsi tentang Tuhan para filsof yang

\footnotetext{
${ }^{79} \mathrm{http}: / /$ www.insistnet.com/index.php?option $=$ com_content\&view $=$ artic le\&id $=46 \% 3$ Akritik-terhadap-teori-al-quran-nasr-hamid-\&catid $=8 \% 3 \mathrm{Aadnin}$ armas\&Itemid $=2$

${ }^{80}$ Adian Husaini dan Hendri Salahuddin, Studi Komperatif:Konsep Al-Qur'an Abu Zayd. 36
}

176 | TAJDID vol. 17, No. 2, Juli - Desember 2018 
dipahaminya. Di mana Tuhan yang Universal tidak bisa berhubungan dengan manusia yang bersifat particular. hal ini tentunya bertentangan dengan konsep Tuhan dalam Islam selain transenden dan juga imanen. bahkan lebih dekat dengan urat nadi hamba-NYa.

Demikian juga, Asumsi historisitas Al-Qur'an Nasr Hamid Abu Zayd, baik dengan mengatakan sebagai teks manusiawi, produk budaya, dan teks bahasa yang kedudukannya sama dengan teks-teks lainnya dalam budaya tidak lain hanyalah khayalan (utopis) yang tidak mendasar, sebab asumsi historisitas yang digunakan Nasr Hamid justru menggirinya kepada sesuatu yang ahistoris. Sesuatu yang tidak mungkin dicapai kebenarannya oleh kaum muslimin. Padahal, sepanjang zaman fakta historis menunjukkan, kaum muslimin dari sejak dulu, sekarang dan akan datang meyakini kebenaran al-Qur'an sebagai kalam Allah.

\section{Daftar Pustaka}

A. Athaillah, 2010, Sejarah Al-Qur'an Verivikasi Tentang Otentisitas Al-Qur'an, (Yogyakarta: Pustaka Pelajar)

Abd Moqsith Ghazali,dkk, 2009, Metodelogi Studi AlQur'an,(Jakarta: GEMA INSANI)

Abdur Rahman al-Bagdadi, 2005, Al-Qur'an Mukjizat yang Abadi, AL-INSAN Jurnal Kajian Islam, Edisi 1, Gema Insani, Januari.

Adian Husaini dan Hendri Salahuddin, 2004, Studi Komparatif: Konsep al-Qur'an Nashr Hamid dan Mu'tazilah, Majalah Islamia, Thn 1 No. 2/Juni-gustus.

Adnin Armas, 2010, Filsafat Hermeneutika dan Dampaknya Terhadap Studi al-Qur'an, INSISTS, Kumpulan Makalah Peneliti Insists.

Aksin Wijaya, 2009, Arah Baru Studi Ulum Al-Qur'an Memburu Pesan Tuhan di Balik Fenomena Budaya, (Yogyakarta: Pustaka Pelajar)

TAJDID Vol. 17, No. 2, Juli - Desember 2018 |177 
at-Thabrani, 1983, Mu'jam al-Kabir, Juz 12,(Maktabah al-'Ulum wa al-Hikam)

Bin Shafie, Ahmad Bazli, 2004, A Modernist Approach to the Qur'an: A Critical Study of the Hermeneutics of Fazlur Rahman, (A Thesis sutmitted in partial fulfillment of requirement for the degree of doctor of philosophy in Islamic thought), International Institute of Islamic Thought and Civilization (ISTAC), International Islamic University Malaysia (IIUM), belum dipublikasikan,

Carl Gustav Jung, 1988, Psycology and Religion (New Haven, Yale University Press)

Fahmi Salim, 2010, Kritik Terhadap Studi Al-Qur'an Kaum Liberal, (Jakarta:Perspektif)

Fahruddin Faiz, 2005, Hermeneutika Al-Qur'an Tema-Tema Kontroversial, (Yogyakarta: eLSAQ)

Fakhr al-Din al-Razi, 1425 H/ 2005 M. Mafatih al-Ghaib, Jld. VI, Dar al-Fikr, Beirut, Cet. Pertama

Hamid Fahmy Zarkasyi , 2009, Liberalisasi Pemikiran Islam, (CIOS-ISID-Gontor)

Hamid Fahmy Zarkasyi, 2012,Mengidentifikasi Teori Liberalisasi, Majalah Islamia, Volume. VI, No.1)

Hendri Salahuddin, 2007, Al-Qur'an Dihujat, (Jakarta:AL QALAM)

http://www.insistnet.com/index.php?option=com_content\&view

$=$ article\&id $=46 \% 3$ Akritik-terhadap-teori-al-quran-nasr-

hamid-\&catid $=8 \% 3$ Aadnin-armas\&Itemid $=2$

Ibn Katsir, 1999, Tafsir al-Qur'an al-'Adzim, Juz I, (Daar Thayyibah)

Imam al-Zarkasyi dalam kitabnya al-Burhan fi'Ulum al-Qur'an (Darul al-turath, Kairo)

Jalaluddin As-Suyuti as- Syafi'i,, 2005, Al-Itqan Fi Ulum al-Qur'an, (Beirut: Darul fikr), 
Lalu Nurul Bayanil Huda, 2010, Konsep Teologi Nasr Hamid Abu Zayd Dan Implikasinya Terhadap Konsep Wahyu, Tesis tidak diterbitkan. (ISID, GONTOR. Ponorogo)

M. Quraish Shihab, 2002, Tafsir Al-Misbah, Cet.1 (Jakarta: Lentera Hati)

M.M. Al-A'zami, 2005, The History of The Qur'anic Text From Revelation to Compilation: A Comperative Study With the Old and New Testaments, (Jakarta: Gema Insani, 2005)

Manna' Khalil al-Qattan, 2007, Studi Ilmu-ilmu Qur'an, Terj: Mudzakir AS (Bogor: Pustaka Lentera AntarNusa)

Moch Nur Ichwan, 2003, Meretas Keserjanaan Kritis Al-Qur'an

Teori Hermeneutika Nasr Hamid Abu Zayd, (Jakarta: TERAJU)

Mohammad Arkoun,dkk. 2002, Al-Qur'an Dimata Barat: Sebuah

Studi Evaluatif," Al-Qur'an Buku Yang Menyesatkan dan Buku Yang Mencerahkan, (Bekasi: Gugus Press)

Muhammad 'Abd al-Adzim az-Zarqani,1995, Manahil al-'Irfan fi

Ulum al-Qur'an (Beirut: Dar al-Kitab al-Arabi)

Muhammad Ali al-Shabuni, 1405 H/1985 M, al-Tibyan fi 'Ulum Al-Qur'an, (Alam al-Kutubu Beirut, Cet. Ke-1

Muhammad Naquib al-Attas, 1995, Prolegomena To The Metaphysics of Islam, (Kuala Lumpur, Malaisia: Prospecta)

Nasr Hamid Abu Zayd dan Ester R. Nelson, 2004, Voice of an

Exile: Reflection on Islam, (London: Westport, Connecticut)

Nasr Hamid Abu Zayd, 2003, Kritik Wacana Agama, Terj.

Khoiron Nahdiyyin. (Yogyakarta: LKiS)

Nasr Hamid Abu Zayd,1994, Mafhum al-Nas: Dirasah fi' Ulum Al-Qur'an (Beirut: al-Markaz al-Thaqafi al-Arabi, edisi II).

Syaich Mahmoud Sjaltout, 1970, Islam Sebagai Aqidah dan Syari'ah, terj. Jilid V, (Jakarta: Bulan Bintang)

Wan Mohd Nor Wan Daud, 2002, Filsafat dan Praktik Pendidikan Islam, Terj.Hamid Fahmy.dkk (Bandung: Mizan)

Warner G. Jeanrond, 1991, The theological Hermeneutcs: Development and Significance, (New York: Crossroad) 
Muzayyin

Wawancara Gatra, 2004, Nomor 44 beredar Jum'at 10 September.

Werner Georg Kummel, 1972, The New Testament: The History of the Investigation of its Problems, Pen. S. McLean Gilmour dan Howard C. Kee (Tennessee: Abingdon Press)

180 | TAJDID vol. 17, No. 2, Juli - Desember 2018 